\title{
Children's Perspective on Subjective Wellbeing Living in Tirana
}

\author{
Ph. D. Candidate Eneida Zalli \\ University "Aleksandër Moisiu", Durrës; eneidazalli@hotmail.com
}

\section{Doi:10.5901/ajis.2016.v5n1p139}

\begin{abstract}
The main focus of this study is to draw an overall development of children, especially during the transition from childhood to adolescence age. Dynamic relationship, effects that certain periods, activities and relationships may have on their general wellbeing. In this study are interviewed twelve children living in Tirana. Interviews with children didn't last more than an hour and thirty minutes. The interview was semi-structured and drafted in a way that was not boring for them, but interesting so that children could express themselves through a variety of communication forms. This was accomplished by including various methods of data collection as activities to break the ice, drawing or writing techniques, different exercises, use of visual aids, writing an essay or paper. The conceptual framework used in this study highlights the relationships of children with the world in which they live. The biological model presented by Bronfenbrenner is a key instrument in presenting this perspective. The views of children regarding health and wellbeing were focused mainly on the physical aspect of it. Proper nutrition and getting into physical activity were considered for most of them key factors for having a healthy body. Children generally considered themselves as healthy. All children interviewed considered smoking as a negative habit and none of them thought they would drink when he/she grew up. Alcohol is not considered to be as negative as cigarettes, if drinked carefully. All of them had had at least one experiece with or alcohol consumption. When thinking about parenting almost all children thought it was something hard. Being a parent for them meant being very careful and responsible with children.
\end{abstract}

\section{Introduction}

This study aims to present the results of qualitative interviews with children on issues that address the wellbeingof these children in Tirana. The main focus of this study will be to draw an overall development of children, especially during the transition from childhood to adolescence age. The conceptual framework used in this study highlights the relationship of children with the world in which they live. The biological model presented by Bronfenbrenner is a key instrument in presenting this perspective. This model is intended to emphasize the importance of taking into consideration the impact that can have a multi-layer model of development over the course of life (Bronfenbrenner,1979,1993; Bronfenbrenner \& Morris, 2006). Bronfenbrenner named its original model "The Theory of Ecological Systems". Through this framework, Bronfenbrenner identified the need to understand the development of individuals within their environment. He presented five sistems in wich people interacted. They were Microsystem wich refers to the institutions and groups that most immediately and directly impact the child's development including: family, school, religious institutions, neighborhood, and peers. Mesosystem wich refered nterconnections between the microsystems, interactions between the family and teachers, relationships between the child's peers and the family. Exosystem wich involves links between a social setting in which the individual does not have an active role and the individual's immediate context. Macrosystem in wich describes the culture in which individuals live. Cultural contexts include developing and industrialized countries, socioeconomic status, poverty, and ethnicity and chronosystem in wich the patterning of environmental events and transitions over the life course, as well as sociohistorical circumstances.

\section{Research Methodology}

Areas of qualitative research:

The issues that will be addressed in this study will aim to provide a deeper understanding and more completed information about the experiences of children. This will be realized through interviews of which consist of questions structured in such way that aim to address issues that are relevant to this study, followed of course by questions or other additional informations that may be deemed appropriate by the applicant at the time of the interview. With regard to sensitive issues, they are supposed to be placed at a later stage of the interview, after the children have had an opportunity to create sufficient confidence with the interviewer.

The main concerns that are explored during the interviews with the children are as follows: 
- Wellbeing, health and physical development: What is the perception that children have relating the factors that help or hinder physical health? What are the feelings or interpretations that they associate with being good and not good? What do they understand with physical development and what is the perception that they have about body image?

- Emotional Development: What is the understanding that children have for their emotional development. How to they they realize the difference between emotions and feelings? What is the perception that they have for themselves in their daily lives? What are the hopes, fears and aspirations that they have?

- Child relationships: How do children perceive their relationship with friends? How do they understand the factors that help or hinder the building of relationships with peers?

- Growth: What do children understand with growth? How do they perceive the transition from the age of twelve to fiveteen years? How did they imagine themselves at the age of fiveeen?

- Community, relatives and sense of citizenship: how do children perceive their local community and relatives or neighbors? What aspects of their life in Tirana do they like and what would they like to change?

- Family decision-making: How is the decision-making in the family? What is the level of involvement of children in decision-making process?

Methods used during the interviews with the children:

The interviews with the children didn't last more than an hour and thirty minutes. The interview was semi-structured and drafted in a way that was not boring for them, but interesting so that children could express themselves through a variety of communication forms. This was accomplished by including various methods of data collection as activities to break the ice, drawing or writing techniques, different exercises, use of visual aids, writing an essay or paper. During this phase, two kinds of techniques were used to start the interview with the child, "Time Capsule" and "My Passport". Initially the children were introduced to the concept of creating a time capsule. They were given a bag-shaped cardboard tube (which we will refer to as a time capsule) where at the end of the interview process will introduce all the products we have realized during the event, they can be drawings, exercise during the interviews, essays etc. They were encouraged to personalize this time capsule as they liked using pencils, crayons, pictures etc. Children were also encouraged to create their passport to traveling in time. They were asked to fill in a blank sheet of their passport, which included details like name, age, address, list of songs, movies, puppets, colors, or games that they like. They also were asked to list one thing that liked and one thing that they didn't like that much. During the interviews were used also some Visual materials that were images or photographs that could help children explore issues related to: the wellbeing, health and physical development, emotional development and family and parenting issues. To explore the relationship between parents and children were asked to pretend that a magician was in front of them and he could realize any desire in linked with their home.

To obtain further information about the wellbeing of children were conducted four exercises which helped exploring different areas. The first exercise is called "My Hand" and was intended to present the child with issues of self-functioning and self-perceptions. During this exercise the interviewer explained to the child that the hand and fingerprints are unique to each person, and during this time the children were asked to draw the shape of the hand in a white sheet, and to write inside each of the fingers of the hand to a word that describes or characterizes them. After completing this exercise the based on criteria that are crucial to be part of it. The participants of this study were children not younger than 12 years old. The age of the children was very important because all children that were selected to be part of the study should have the necessary knowledge to understand the questions directed to them. Considering the fact that while collecting data and conducting interviews, a very important part of the procedure would be drawings, writing essays and analyzing different images, children should be educated and prepared enough to realize these tasks successfully. In this study participated twelve children, residing in the capital of Albania. Children were selected from different areas of Tirana in order to see if different demographic characteristics can have an impact on the general perceptions about wellbeing of children.

\section{Data Analysis}

The questions that were addressed to the participants were conducted throught ecological perspective on the development of children. Each interview was analyzed based on a theme. The data analysis was performed using each of the transcribed interviews of the children. All the drawings, essays, letters that the children made during the interviews were categorized and each one had a specific code. 


\title{
4. Ethical Issues
}

This study followed all the appropriate ethical frameworks. During each stage of the research process every child was regarded with the appropriate care and attention. During the interviews none of the children were harmed harmed psychologically or emotionally ; all their requirements were respected; the informed permission was insured for each and one of them; and i made clear to each and one of them that they could withdraw from the study at any time they would feel embarrassed or uncomfortable with the way the interview was going; The right precaution were taken to ensure the confidentiality for all the participants

\section{Results and Conclusions}

\subsection{Health and wellbeing}

\subsubsection{Food, healthy and unhealthy habits}

Children were asked to write, draw or talk about factors they think keep them strong and healthy. For most of them, this had to do with the physical aspect of humans. Their main idea of living healthy was taking care of the way they fed and performed physical activity. Most of them thought they had to consume as much fruits and vegetables as possible and fewer fats and sweets.

They answered the question about which food are good and which ones are unhealthy. They answered as follows:

\begin{abstract}
"we buy the one that's the cheapest. If the kilogram costs 100LEK we don't buy it.. what comes from lunch.. the leftovers." (BOY)

"Well.. when you eat salad, vegetables, homemade dishes and not processed food from outside.. that's what's good for your health. (GIRL)

When we discussed about what are some of the healthy habits that will help you live better, children answered:

"living in the countryside because there are more vegetables there. The air is much more fresh and clean in the countryside. You don't even get fat there because there are no pies and they even prepare the bread themselves, they don't buy it. (BOY)

"Going to the gym for example.. it's really good. Also exercising. (GIRL)
\end{abstract}

\section{1 .2 Illness}

As for the matters that were related to illness or how they have reacted when they were not feeling well, the majority of them said that they do not turn to their parents immediately but they wait until the pain goes off itself. Only if the pain continues, then they tell either their mum or dad. Only one of the girls confessed that it was her older sister that would know first if she was feeling bad.

\footnotetext{
"Ever since I was younger, since I was four, I have had troubles breathing, I was taken to the hospital and I was put oxygen in my nostrils. I am much better now but when I get tired my breath shortens often. Now it is not a big problem for me, unless I get tired.. unless I perform a lot of physical activity. I go to my sister and show her... she hugs me, and tells mum. (laughs)" (GIRL)
}

\subsubsection{Obesity}

When children were asked about the meaning of the word obesity, most of them did not know what it actually meant.. just one of the interviewed boys knew the meaning of the word because according to what he said, his grandparents often advised him to be careful with eating because he could become obese. After explaining to them what obese meant, they were able to make the connection between being overweight and eating sandwiches, chips or any other food or fizzy drink that is bought outside and which is not home made. 


\subsubsection{Smoking and alcohol}

Children considered smoking as a really bad habit to which they felt disgust and which they thought they will never be able to do, even though, each of them had had the opportunity to try it once- they even knew friends who consumed cigarettes. One of the kids explained how in his neighborhood there was a boy, a little older than him who regularly smoked. All children expressed that the cigarettes' smoke was really bothersome to them and when one of their parents smoked at home, it was impossible for them to convince their parents that this thing was not likable for them. Some of the kids answered to the question as which one of their family members smoked as follows:

"In my house only dad smokes, and it really bothers me a lot." (GIRL)

"In my house my mum and brother smokes.. now my sister has cut off the cigarettes because she is pregnant. It bothers me but I can't tell them to smoke outside because then it means I should go out.(laughs)My sister.. when she quit, she said that she hoped I would never smoke when I grow up." (GIRL)

The majority of kids considered alcohol as a beverage that could be good but also bad. Carefully consuming alcohol does not bring any damage unless you overdo it. Two of the interviewed kids considered redbull as an alcoholic beverage and they liked to consume it. One of the boys pointed out that he consumed it a couple of times a month.

"I think that.. sometimes it's good and sometimes it is not. When you drink too much it's bad."(GIRL)

"I have heared that when you overdrink, you can get into a car crash." (GIRL)

"Once I consumed a beer and I got drunk.. I felt like throwing up. I don't want to try it again. Also 'raki' makes me throw up. (GIRL)

\subsubsection{Self image}

During this session, children were asked to think about them, what they thought about themselves, how others described it, if the outer appearance was important in life and whether they wanted to change anything about themselves or not. It was also discussed on how they looked at themselves at the age of 15. The interviewed kids admitted that the outer appearance indeed is important, but what they valued more was what was found beyond what we see on the outside. One of the girls expressed herself like this:

"The outer appearance and the inner appearance are both very important.. the inside because that's where a person is known from.. the inner appearance more than the physical one."

Children were given a white sheet of paper where they would draw the shape of their fingers and for each finger they would decide a word which they thought characterized them. Most of them had a very positive opinion about themselves.

"Polite; generous; shy; kindhearted; skinny." (GIRL)

"Loveable ; Kind; Never takes anything without asking first ; You will get taller ; meatball." (BOY)

ty about the way that one of her classmates took care of herself and dressed through pointing out that she had a very good body and was not skinny(the interviewed girl thought that she was very thin).

\subsubsection{Perceptions on being a parent}

In this session children were asked a series of questions related to being a parent, how they think being a parent is, what are some of the characteristics of a good parent. Also they were asked to think whether rules existed in their houses and whether they felt comfortable with these rules. They were asked as well if they would like to change anything if they could.

"Being a good parent is hard because from the moment you give birth to your child and up to the moment your child grows up, you have to educate, to teach him/her with the things that should and shouldn't be done. That they shouldn't offend each other, it's parents that have to teach all this to their children. And ideal parent is one that teaches his/her child, that gives everything to him/her, one who doesn't yell who doesn't abuse.. that's what can be called an ideal parent. (GIRL) 
The main rules that children mentioned were related to the timetables. The time where they had to study, the sleeping hours. Don't touch the iron, don't touch the knife, don't eat on your bed, don't open the balcony door with your hands because you will leave prints on it and so on, were some of the actions that children were not allowed to do. Children were also asked if their opinion was ever asked about the decisions that were taken inside the family. This is how some of them answered:

\begin{abstract}
"well for example, if they are going to change the car they ask me.. do you want to. Or when we have to go to a wedding and my mum has to take permission from work, they ask me too." (GIRL)

"When I was sick sometimes my mum asked me on the phone, should I take permission from work so that I can stay with you?" (GIRL)
\end{abstract}

\title{
5.1.7 Children and their relatives
}

Children were asked about the relationships that they had with their other family members. They were requested to write the names of the family members in a paper with concentric circles around it, starting from the family member they were most close with to the one they thought they were less close to. In order to find out more about their emotional perceptions they were asked to say something that characterized these relationships. The largest percentage were most close to their parents, mainly their mothers because they thought it was easier to talk to their mums. One of the girls had a closer relationship with her sister, about 10 years older than her than with her mum. The girl had lost her father and her mum had to work through the whole day in order to keep the family.

"I can express more easily with my mum... I share more secrets with her. With my dad I don't share secrets.. whereas with my friends I don't share... because some have to do with my family and it's not appropriate for other to know..." (GIRL)

"We do chores together.. everything. I help my mum with the house work because she works all day and I do everything as soon as I come from school. I do the dishes, clean the house, change..the..bed sheets.. everything.. because my brother can't do them since his a boy. It's not like he shouldn't do anything but.. he does clean sometimes.. what he messes up himself but he can't change the sheets for example." (GIRL)

\subsubsection{Children and their neighborhood}

The interviewed kids lived in different areas of Tirana, mainly in the suburb, except for three who were closer to the centre. However, all of them expressed discontent about the neighborhood where they lived in, mainly because of the lack of appropriate playgrounds, a large number of cars, unpaved streets even the presence of people that consumed narcotic substances. They were asked to think about a way they would like to change their neighborhood and for this they were asked to write a letter to the prime minister where they would explain their concern. Below we have chosen two of the letters: for privacy matters the names and details of the kids will be shown through initials.

First letter:

"Dear, Mr. Edi Rama, my name is M. My house is located at "Astiri". Where I live, the streets are unpaved. When cars pass by a huge smoke rises up. I want the roads to be paved but I also want you to put a large fine to the cars that ride in fast speeds. With respect, M. (GIRL)

Apart from the letters children were given the opportunity to speak more about the discontents and concerns that they had from their neighborhood and some of them admitted that:

"in my neighborhood there are many gangsters.. even young ones.. there is one younger than me who smokes, drinks beers, goes out late at night on his own.. how do his parents allow him that.. There isn't something I like about my neighborhood." (BOY)

\subsection{Life satisfaction, wishes and fears}

At this stage of the interview children were directed some questions on what they meant by stress, sadness, happiness; what is that one thing that they want more in life and what is that thing which they fear of. Children were asked to perform a test named the stair of life. Each one of them would think on how happy and content they were with their life and then 
they would number this pleasure from 1 up to 10. After this each of the kids would explain why they had chosen this number.

\subsection{Perceptions about boredom, frustration, happiness and stress}

Below are some of the ideas that the children had to each of the above concepts:

"Boredom is when you stop talking to others ..." (Boy)

"When you're happy ... time passes quickly." (Boy)

"Stress is when you are bored too much, lost some money, or when people steal from you .." (Boy)

"People are stressed when they are yelling to others ... they talk quickly, they don't have tpatience ... they get upset quickly." (Girl)

\subsubsection{Ladder of life}

Children explained why they did not choose the maximum level of life satisfaction scale:

"I chose $n r .9$ because I am notthat satisfied ... my friends ... I don't know ... they do not behave that good with me ... I don't know, it does bother me a bit. For example my friend misbehaved with me ... she started hanging out with another friend and didn't say anything to me ... I don't know ... well then I got used to it ... I got angry at them at the moment ... and it's still bothering me. Now we do not get along ....and my other friends ... I don't not know ... they are hanging with them too, although I am their friend. I felt betrayed ... "(Girl)

Children were also asked whether they would like to change anything in their lives; two of the children said they would like to have a little brother or sister. Many of them wanted to have a cat or dog in the house and just wanted to have some more toys. Children said that for them school was a place they liked, even though they enjoyed their vacations, the school was always better than doing nothing at all. Some of them expressed fears of children getting hurt by falling off a bike, the third world war, or the revival of Caki doll. Some of their wishes were that their mothers wouldn't get so much tired dealing with household chores, one of them wanted to live in England, someone wanted to have a bike, another oneto see more TV and some to be able not to require their parents account.

\subsection{Activities}

When children were asked what they do or would like to do to have fun, many of them expressed a desire to go to TEG, to Blur, or play basketball, volleyball, which did not happen because they could not afford. After school activities for children of this age were very limited, this being based on the information in the weekly calendar of activities of each child, where most of them stated that they only time they performed physical training was during school hours, wich was part of the curriculum.

\subsection{Perceptions about adolescence}

Children were asked to imagine how it will their life be after three years, when they would be 15 years old. How would their life be, what changes would have happened, would their body have changed, how would school be, what kind of relationship would they have with their parents. All children interviewed were aware that in this age would face major changes in their physique and not only.

\section{Conclusions}

The views of children regarding health and wellbeing were focused mainly on the physical aspect of it. Proper nutrition and getting into physical activity were considered for most of them key factors for having a healthy body. Children generally considered themselves as healthy with the exception of one of the boys who wanted to lose some weight or one of the girls who thought she was a little skinny. All of them were sick once, but nothing serious. Most of them didn't want to alarm their parents. The concept of "being obese" wasn't familiar to them, however, they felt that the reason why someone can be overweight is as a consequence of eating fast food, eating outside and not at home. All children interviewed considered smoking as a negative habit and none of them thought they would drink when he/she grew up. 
Alcohol is not considered to be as negative as cigarettes, if drinked carefully. All of them had had at least one experiece with or alcohol consumption.

All the interviewed childrens, with some small exceptions, were very satisfied with their outer appearance. They had enough self-confidence and a positive self-perception. They stated that they would not judge someone from their looks to chose as their friends, but also even though they couldn't explain they know that the way one looks is important.

Relationships between children and their mothers was closer than with the father. They felt more comfortable talking about their things with their mothers than their fathers. This was more obvious for girls than for boys.

When thinking about parenting almost all children thought it was something hard. Being a parent for them meant being very careful and responsible with children. According to them, an ideal parent was the one who cared for the needs of the child, who educated him or her properly, who didn't use violence, who didn't yell etc. The rules in their family were based primarily on the actions that they are allowed or not to do, for ie not to run inside the house,not to eat bread in bed, not to touch the iron etc. Only one of the children spoke about the punishment they could receive when they didn't follow the rules, that was a slap here and there.

\section{References}

Bronfenbrenner, U. (1993). The ecology of cognitive development. In R. H. Woznick \& K. Fischer (Eds.),Acting and Thinking in Specific Environments. Hillsdale, NJ: Erlbaum.

Cantril, H. (1965). The pattern of human concerns. New Brunswick, NJ: Rutgers University Press.

DOHC (1999). Children First: National Guidelines for the Protection and Welfare of Children. Dublin:Department of Health and Children.

Egg, P., Schratz-Hadwich, B., Trubswasser, G., \& Walker, R. (2004). Seeing Beyond Violence: Children as Researchers: SOSKinderdorf International.

Kuffner, T. (2001). The Children's Busy Book. Minnesota Meadowbrook Press.

Hill, M., Laybourn, A., \& Borland, M. (1996). Engaging with primary-aged children about their emotions and well-being: Methodological considerations. Children and Society, 10, 129-144.

Bronfenbrenner, U. (1979). The ecology of human development: Experiment by nature and design.Cambridge: Harvard University Press. 
